\title{
Properties of Direct Coal Liquefaction Residue Modified Asphalt Mixture
}

\author{
Jie Ji, ${ }^{1}$ Hui Yao, ${ }^{2}$ Di Wang, ${ }^{3}$ Zhi Suo, ${ }^{3}$ Luhou Liu, ${ }^{4}$ and Zhanping You ${ }^{5}$ \\ ${ }^{1}$ School of Civil Engineering and Transportation, Beijing University of Civil Engineering and Architecture and \\ Beijing Urban Transportation Infrastructure Engineering Technology Research Center, Beijing 100044, China \\ ${ }^{2}$ Department of Civil and Environmental Engineering, Michigan Technological University and School of Traffic and Transportation, \\ Changsha University of Science and Technology, 1400 Townsend Drive, Houghton, MI 49931, USA \\ ${ }^{3}$ Beijing Urban Transportation Infrastructure Engineering Technology Research Center and \\ Beijing Collaborative Innovation Center for Metropolitan Transportation, Beijing 100044, China \\ ${ }^{4}$ School of Civil Engineering and Transportation, Beijing University of Civil Engineering and Architecture and \\ Beijing Cooperative Innovation Research Center on Energy Saving and Emission Reduction, Beijing 100044, China \\ ${ }^{5}$ Department of Civil and Environmental Engineering, Michigan Technological University, 1400 Townsend Drive, \\ Houghton, MI 49931, USA
}

Correspondence should be addressed to Hui Yao; huiyao@mtu.edu

Received 30 November 2016; Accepted 2 February 2017; Published 21 February 2017

Academic Editor: Antonio Riveiro

Copyright (C) 2017 Jie Ji et al. This is an open access article distributed under the Creative Commons Attribution License, which permits unrestricted use, distribution, and reproduction in any medium, provided the original work is properly cited.

\begin{abstract}
The objectives of this paper are to use Direct Coal Liquefaction Residue (DLCR) to modify the asphalt binders and mixtures and to evaluate the performance of modified asphalt mixtures. The dynamic modulus and phase angle of DCLR and DCLR-composite modified asphalt mixture were analyzed, and the viscoelastic properties of these modified asphalt mixtures were compared to the base asphalt binder SK-90 and Styrene-Butadiene-Styrene (SBS) modified asphalt mixtures. The master curves of the asphalt mixtures were shown, and dynamic and viscoelastic behaviors of asphalt mixtures were described using the Christensen-AndersonMarasteanu (CAM) model. The test results show that the dynamic moduli of DCLR and DCLR-composite asphalt mixtures are higher than those of the SK-90 and SBS modified asphalt mixtures. Based on the viscoelastic parameters of CAM models of the asphalt mixtures, the high- and low-temperature performance of DLCR and DCLR-composite modified asphalt mixtures are obviously better than the SK-90 and SBS modified asphalt mixtures. In addition, the DCLR and DCLR-composite modified asphalt mixtures are more insensitive to the frequency compared to SK-90 and SBS modified asphalt mixtures.
\end{abstract}

\section{Introduction}

Currently, the design method of asphalt pavement in China is based on the static and elastic layer system models [1]. The stress and strain of each layer can be calculated using the static modulus of asphalt mixtures. However, the static modulus is used to represent the property of each layer which is inaccuracy since the loading on the pavement is dynamic. It is necessary to use the dynamic modulus to calculate the mechanical property of each layer. The dynamic modulus was used in the United States in 1980. The National Cooperative Highway Research Program- (NCHRP-) 465 report indicates that the dynamic modulus of asphalt mixtures can be used to evaluate the permanent deformation [2]. The dynamic modulus test can also be used to evaluate the service quality of the subgrade and pavement [3]. The NCHRP-702 and 580 reports present the standard and accuracy of the dynamic modulus test, and the reports suggest that the high- and low-temperature performance of asphalt mixtures can be predicted using the master curve of the dynamic modulus $[4,5]$. The NCHRP-629 report also reveals that the durability of asphalt pavement can be evaluated using the dynamic modulus of asphalt mixture [6]. The permanent deformation and cracking growth pattern of asphalt mixtures were studied using the dynamic modulus test, and the initiation of cracks started with the change in the phase angle of asphalt mixtures, 
and the permanent deformation and fracture model were proposed [7]. The relationship between the rutting and dynamic modulus was also established [8]. The dynamic moduli of the modified asphalt mixtures were fitted by master curves [9]. The dynamic modulus of asphalt mixtures can be investigated using the actual stress and strain response of pavement [10]. The dynamic modulus is a basic parameter for the design of asphalt pavement in many countries, and it has been widely accepted $[11,12]$. In the specifications of American Association of State Highway and Transportation Officials (AASHTO), the design guideline for new pavement and regenerated pavement 2002 and the guideline for asphalt pavement mechanics-empirical design method (2002) was put forward by the NCHRP program $[13,14]$, and the dynamic modulus of asphalt mixtures can be considered one of the essential parameters in pavement design. It is possible to track the dynamic and viscoelastic behaviors of asphalt mixtures over a full temperature range through the master curve of asphalt mixtures [15]. The master curve of the dynamic modulus was plotted using the Christensen-Anderson-Marasteanu (CAM) model, and the viscoelastic properties of asphalt mixture were characterized [16, 17]. In addition, the performance of asphalt mixtures can be influenced by the properties of asphalt binders and aggregates. Many modifiers were used to modify and improve the performance of asphalt binders including polymer, waste materials, and by-products, and different surface treatments were also used to enhance the adhesion between aggregates and binders. Currently, the Direct Coal Liquefaction Residue (DCLR) is the main byproduct produced in the process of the direct coal liquefaction, which accounts for $30 \%$ of the total amount of raw coals [18]. The DCLR contains $30 \%-50 \%$ heavy oil and asphaltene materials $[19,20]$, and it has a potential to be developed for a modifier. The DCLR is mainly used as a fuel for heating, which not only causes serious environmental pollution but also reduces its economic value and leads to a waste of valuable resources.

At the beginning of the last century, researchers began to study the properties and applications of DCLR including the main structure and pyrolysis characteristics [21]. The DCLR modified asphalt binder was prepared using blending ESSO70 asphalt binder and DCLR, and the optimum DCLR content was $7 \%-21 \%$ [22]. If the DCLR content was $5 \%$, the properties of the DCLR modified asphalt binder met the technical standard of asphalt binders (Penetration grade number 50) [23]. The high-temperature performance of asphalt binders was improved [24], but low-temperature performance was reduced by the addition of DCLR [25]. The surface energies of the DCLR modified asphalt binders were calculated by Wilhelmy plate method and the microscopic properties were examined [26, 27]. The characteristics of the DCLR modified asphalt binder were researched by means of Thermogravimetric Analysis-Fourier Transform Infrared Spectroscopy (TG-FTIR), Fourier transform infrared spectroscopy (FTIR), and Fluorescence Optical Microscopy (FOM). The heavy oil can enhance the ductility and penetration of DCLR modified asphalt binders while the asphaltenes and preasphaltenes increase the softening point of DCLR modified asphalt binders [28]. The modified asphalt binder was prepared by the addition of the tetrahydrofuran soluble fraction (THFS) and the benzaldehyde was used as the cross-linking agent. The conditions during the preparation of the modified asphalt binders were studied, such as mixing temperature, ratios of THFS, and cross-linking agent. The results show that the DCLR modified asphalt binder has better properties with the utilization of the cross-linking agent [28]. The mesophase pitches were prepared by the hydrogenation and polycondensation from the Shenhua DCLR. The element analysis and FTIR were used to investigate the composition and structure of DCLR modified asphalt binders. The effects of tetrahydrogen naphthalene and reaction temperatures were studied, as well as the morphologies of mesophase pitches [29].

Based on the discussions of the DCLR materials, it can be seen that DCLR can be used as an asphalt modifier to improve high-temperature properties of asphalt binders, while it may have a negative impact on low-temperature performance. Therefore, it is meaningful to use DCLR to conduct research on the dynamic modulus or properties under consideration of the environmental issue and economic value. The master curve was plotted to understand the dynamic modulus of asphalt mixtures. The Christensen-Anderson-Marasteanu (CAM) model was also used to study the viscoelastic behaviors of DCLR and DCLR-composite modified asphalt mixtures.

\section{Objectives and Test Methods}

2.1. Objectives and Experimental Plan. The objectives of this project are to use the DCLR to modify the asphalt binders and mixtures and to evaluate the performance of modified asphalt mixtures. The experimental plan of this study includes the following: (1) prepare three types of modified asphalt binders based on the SK-90 base asphalt binder, including StyreneButadiene-Styrene (SBS) modified asphalt binder, DCLR modified asphalt binder, and DCLR-composite modified asphalt binder; (2) design four asphalt mixtures based on the gradation of AC-20 (AC: Asphalt Concrete), which were SK-90 asphalt mixture, SBS modified asphalt mixture, DCLR modified asphalt mixtures, and DCLR-composite modified asphalt mixtures; (3) obtain the dynamic moduli of the asphalt mixtures and analyze viscoelastic properties of the asphalt mixtures; (4) establish a CAM model of the asphalt mixtures.

2.2. Test Methods. In accordance with the Test Methods of Asphalt and Asphalt Mixtures for Highway Engineering (JTGE20-2011), the properties of the SK-90 base asphalt binder and three types of modified asphalt binders were tested based on the penetration and the Strategic Highway Research Program (SHRP) Performance Grade (PG) systems. According to the Test Methods of Aggregate for Highway Engineering (JTG E42-2005), the properties of aggregates were measured. The specimens were prepared for the compaction test according to the T 0738-2011 of Test Methods of Asphalt and Asphalt Mixtures for Highway Engineering (JTGE20-2011). The test specimens are formed by the compaction apparatus with dimensions of $450 \mathrm{~mm}$ in length, $150 \mathrm{~mm}$ in width, and $170 \mathrm{~mm}$ in height. The specimens were core drilled into 
TABLE 1: Physical properties of DCLR, SBS, and rubber powders.

(a)

\begin{tabular}{lccccc}
\hline DCLR & Apparent gravity $/\left(\mathrm{g} / \mathrm{cm}^{3}\right)$ & Density $/\left(\mathrm{g} / \mathrm{cm}^{3}\right)$ & Water content $/ \%$ & $25^{\circ} \mathrm{C}$ Penetration $/(0.1 \mathrm{~mm})$ & Softening point $/{ }^{\circ} \mathrm{C}$ \\
\hline Test results & 1.12 & 1.23 & 0.60 & 2.0 & 170.0 \\
\hline
\end{tabular}

(b)

\begin{tabular}{lcccc}
\hline SBS & Block ratio & Tensile strength/MPa & Elongation at break/\% & Percentage of liquid volume/\% \\
\hline Test results & $40 / 60$ & $\geq 12$ & $\geq 650$ & 0 \\
\hline
\end{tabular}

(c)

\begin{tabular}{lcccc}
\hline Rubber powders & Density $/\left(\mathrm{g} / \mathrm{cm}^{3}\right)$ & Water content $/ \%$ & Mental content $/ \%$ & Fiber content $/ \%$ \\
\hline Test results & 1.13 & $\geq 0.65$ & $\geq 0.07$ & $\geq 0.11$ \\
\hline
\end{tabular}

TABLE 2: Properties of the asphalt binders (penetration system).

\begin{tabular}{lcccc}
\hline Items & SK-90 asphalt binder & $\begin{array}{c}\text { SBS modified asphalt } \\
\text { binder }\end{array}$ & $\begin{array}{c}\text { DCLR modified } \\
\text { asphalt binder }\end{array}$ & $\begin{array}{c}\text { DCLR-composite } \\
\text { modified asphalt binder }\end{array}$ \\
\hline $25^{\circ} \mathrm{C}$ penetration/(0.1 mm) & 81.0 & 61.2 & 35.1 & 33.4 \\
Softening point $/{ }^{\circ} \mathrm{C}$ & 51.0 & 65.4 & 59.2 & 77.5 \\
$10^{\circ} \mathrm{C}$ ductility/cm & 51.8 & $68.2 / 32.3\left(5^{\circ} \mathrm{C}\right)$ & 5.7 & 12.2 \\
After Rolling Thin Film & & & & \\
Oven (RTFO) test & & -0.2 & +0.2 & -0.1 \\
$\quad$ Mass loss/\% & +0.1 & 64.2 & 69.3 & 79.5 \\
Penetration ratio/\% & 64.1 & $39.6 / 21.8\left(5^{\circ} \mathrm{C}\right)$ & 4.2 & 9.7 \\
$10^{\circ} \mathrm{C}$ ductility/cm & 8.0 & & \\
\hline
\end{tabular}

cylindrical specimens with a diameter of $100 \mathrm{~mm}$ and height of $150 \mathrm{~mm}$ after cooling to room temperature for $24 \mathrm{~h}$. The dynamic modulus test was carried out under the control of Universal Testing Machine UTM-25 with the sinusoidal load stress. The test temperatures are $5^{\circ} \mathrm{C}, 15^{\circ} \mathrm{C}, 35^{\circ} \mathrm{C}$, and $50^{\circ} \mathrm{C}$ and the test frequencies are $25 \mathrm{~Hz}, 10 \mathrm{~Hz}, 5 \mathrm{~Hz}, 1 \mathrm{~Hz}$, and $0.1 \mathrm{~Hz}$. In addition, the dynamic moduli of asphalt mixtures were measured without the confinement.

\section{Test Materials}

3.1. Modifier. The DCLR was produced from China Shenhua Coal to Liquid and Chemical Co., Ltd. The Styrene-Butadiene-Styrene (SBS) was purchased from Sinopec Yanshan Petrochemical Co., Ltd., and rubber powders were bought from Antai Rubber Co., Ltd. In accordance with Test Methods of Asphalt and Asphalt Mixtures for Highway Engineering (JTGE20-2011), the physical properties of test materials were measured and are listed in Table 1.

3.2. Asphalt Binders. The SK-90 asphalt binder was used as the base asphalt binder, which was produced from South Korea. 3.4\% SBS was added in the asphalt binder by mass of SK-90 asphalt binder, and the SBS modified asphalt binder was formed. The DCLR-composite material contains $10 \%$ DCLR, 2\% SBS, and 15\% rubber powder by mass of SK90 asphalt binder. These materials were added to the SK-90 asphalt binder, and the DCLR-composite modified asphalt binder was prepared at a temperature of around $135^{\circ} \mathrm{C}$.
According to Test Methods of Asphalt and Asphalt Mixtures for Highway Engineering (JTGE20-2011), properties of the asphalt binders were measured and are shown in Table 2 . In addition, the Dynamic Shear Rheometer (DSR) and Bending Beam Rheometer (BBR) tests were employed to evaluate the performance of asphalt binders under the Rolling Thin Film Oven (RTFO) and Pressure Aging Vessel (PAV) aging conditions. The DSR and BBR results of the asphalt binders are shown in Table 3.

Table 2 shows the test results of asphalt binders including the penetration, softening point, and ductility. The SK-90 asphalt binder had a high penetration at $25^{\circ} \mathrm{C}$, and the penetrations of modified asphalt binders decreased after the modification by SBS, DCLR, and DCLR-composite. It indicates that the modified asphalt binders become hard after the modification. The softening points of the modified binders increased after modification compared to the SK-90 base asphalt binder, and the DCLR-composite modified asphalt binder improved the most. It is likely that high-temperature performance of the modified asphalt binders was enhanced after modification. It can be expected that the ductility of the modified binders decreased greatly after modification. The SBS improved the ductility of modified asphalt binder. The low-temperature performance of the binders possibly degraded after modification for the DCLR modified binder. The ductility of the modified asphalt binders improved after RTFO compared to the SK-90 binder. Table 3 shows the test results of different asphalt binders after different aging conditions based on the Superpave PG system. The PG grade 
TABLE 3: Properties of the asphalt binders (SHRP PG system).

\begin{tabular}{|c|c|c|c|c|c|c|}
\hline Stages & Temperature $/{ }^{\circ} \mathrm{C}$ & $\begin{array}{l}\text { SK-90 asphalt } \\
\text { binder }\end{array}$ & $\begin{array}{l}\text { SBS modified } \\
\text { asphalt binder }\end{array}$ & $\begin{array}{l}\text { DCLR modified } \\
\text { binder }\end{array}$ & $\begin{array}{c}\text { DCLR- } \\
\text { composite } \\
\text { modified } \\
\text { asphalt binder }\end{array}$ & Superpave spec. \\
\hline \multirow{6}{*}{$\begin{array}{l}\text { Unaged } \\
\left(G^{*} / \sin \delta(\mathrm{kPa})\right)\end{array}$} & 58 & 2.18 & 8.46 & 6.56 & 37.31 & \multirow{6}{*}{$\geq 1.1$} \\
\hline & 64 & 0.96 & 6.10 & 2.75 & 20.24 & \\
\hline & 70 & - & 2.98 & 1.2 & 11.09 & \\
\hline & 76 & - & 1.23 & 0.61 & 6.39 & \\
\hline & 82 & - & 0.84 & - & 3.86 & \\
\hline & 88 & - & - & - & 0.66 & \\
\hline \multirow{6}{*}{$\begin{array}{l}\text { RTFO } \\
\left(G^{*} / \sin \delta(\mathrm{kPa})\right)\end{array}$} & 58 & 4.62 & 17.19 & 21.670 & 49.44 & \multirow{6}{*}{$\geq 2.2$} \\
\hline & 64 & 1.97 & 9.29 & 8.862 & 27.13 & \\
\hline & 70 & - & 4.74 & 3.821 & 15.82 & \\
\hline & 76 & - & 2.5 & 1.73 & 7.54 & \\
\hline & 82 & - & 1.35 & - & 4.54 & \\
\hline & 88 & - & - & - & 2.09 & \\
\hline \multirow{4}{*}{$\begin{array}{l}\mathrm{PAV} \\
\left(G^{*} \cdot \sin \delta(\mathrm{kPa})\right)\end{array}$} & 25 & 1958 & 2274 & 4658 & 2863 & \multirow{4}{*}{$\leq 5000$} \\
\hline & 22 & 3014 & 3826 & 6266 & 3920 & \\
\hline & 19 & 4555 & 5215 & - & 5516 & \\
\hline & 16 & 6681 & - & - & - & \\
\hline \multirow{4}{*}{$\begin{array}{l}\text { PAV (stiffness } \\
(\mathrm{MPa}))\end{array}$} & -6 & 82.63 & 95.45 & 86.083 & 39.65 & \multirow{4}{*}{$\leq 300$} \\
\hline & -12 & 184.03 & 198.65 & 220.91 & 81.52 & \\
\hline & -18 & 306.23 & 211.32 & 325.20 & 164.39 & \\
\hline & -24 & - & 316.49 & - & 300.21 & \\
\hline \multirow{4}{*}{ PAV ( $m$-value) } & -6 & 0.34 & 0.34 & 0.33 & 0.42 & \multirow{4}{*}{$\geq 0.3$} \\
\hline & -12 & 0.32 & 0.31 & 0.27 & 0.34 & \\
\hline & -18 & 0.29 & 0.30 & - & 0.30 & \\
\hline & -24 & - & 0.28 & - & 0.29 & \\
\hline PG & & $58-22$ & $76-22$ & $70-16$ & $82-28$ & \\
\hline
\end{tabular}

Note: $G^{*}$ : complex shear modulus; $\delta$ : phase angle; $G^{*} / \sin \delta$ : rutting factor; $G^{*} \cdot \sin \delta$ : fatigue factor; RTFO: Rolling Thin Film Oven; PAV: Pressure Aging Vessel; and PG: Performance Grade.

of SBS modified asphalt binder improved from 58-22 to 76-22. The PG of DCLR modified asphalt binder was from 58-22 to $70-16$, and the PG of the DCLR-composite asphalt binder was from 58-22 to 82-28. This indicates that the high-temperature performance of the modified asphalt binders improved, and the low-temperature performance of DCLR-composite modified asphalt binder was also enhanced compared to the base asphalt binder.

3.3. Aggregates. The limestone was used as the aggregate material in this study, which included $9.5-20 \mathrm{~mm}$ coarse aggregate, $4.75-9.5 \mathrm{~mm}$ coarse aggregate, and $0-4.75 \mathrm{~mm}$ fine aggregate. The limestone powder was used as a mineral powder. The properties of aggregates were measured in accordance with Test Methods of Aggregate for Highway Engineering (JTG E42-2005) and are shown in Tables 4 and 5.

Tables 4 and 5 show the specific gravity, wear loss, angularity, and sand equivalent of the coarse and fine aggregates, as well as the gravity, water content, hydrophilic coefficient, and plasticity index. The results of aggregates meet the requirements of standards, and the aggregates can be used to make the asphalt mixture samples. The same aggregate was used for the mixture in this project.

3.4. Asphalt Mixture. The AC-20C (AC: Asphalt Concrete) asphalt mixture was adopted, and the gradation of the asphalt mixture is presented in Figure 1. The asphalt mixture was mixed and compacted based on the Marshall and Superpave systems. The mixing and compaction temperatures of modified asphalt mixtures were based on the temperatures of the base asphalt mixture. The mixing temperature of DCLR and SBS modified asphalt mixtures is around $160^{\circ} \mathrm{C}$, and the compaction temperature is around $155^{\circ} \mathrm{C}$, as well as the SK90 asphalt mixture. The mixing and compaction temperatures of DCLR-composite modified asphalt mixtures are $175^{\circ} \mathrm{C}$ and $170^{\circ} \mathrm{C}$, respectively. Table 6 shows the volume indexes of the asphalt mixtures at the optimum asphalt content. The dynamic stability is used to access the resistance to permanent deformation and the tensile strength ratio (TSR) is used to evaluate the moisture damage of asphalt mixtures. The 
TABLE 4: Properties of coarse and fine aggregates.

(a)

\begin{tabular}{lccc}
\hline Properties of coarse aggregate & $4.75-9.5 \mathrm{~mm}$ & $9.5-20 \mathrm{~mm}$ & Spec. \\
\hline Apparent specific gravity $/\left(\mathrm{g} / \mathrm{cm}^{3}\right)$ & 2.80 & 2.85 & $\geq 2.60$ \\
Gross volume relative density $/\left(\mathrm{g} / \mathrm{cm}^{3}\right)$ & 2.71 & 2.76 & - \\
Wear loss in Los Angeles $/ \%$ & - & 17.8 & $\leq 28$ \\
Washing $<0.075 \mathrm{~m}$ particle content $/ \%$ & 0.1 & 0.2 & $\leq 1$ \\
\hline
\end{tabular}

(b)

\begin{tabular}{lcc}
\hline Properties of fine aggregate & Test results & Spec. \\
\hline Apparent specific gravity $/\left(\mathrm{g} / \mathrm{cm}^{3}\right)$ & 2.78 & $\geq 2.60$ \\
Bulk relative specific gravity $/\left(\mathrm{g} / \mathrm{cm}^{3}\right)$ & 2.68 & - \\
Angularity/s & 43.2 & $\geq 30$ \\
Sand equivalent $\%$ & 65.0 & $\geq 60$ \\
\hline
\end{tabular}

TABle 5: Properties of mineral powder.

\begin{tabular}{lcc}
\hline Items & Test results & Spec. \\
\hline Apparent specific gravity $/\left(\mathrm{g} / \mathrm{cm}^{3}\right)$ & 2.73 & $\geq 2.5$ \\
Water content $\%$ & 0.52 & $\leq 1$ \\
Size range & & \\
$\quad<0.075 \mathrm{~mm}$ & 100 & 100 \\
$<0.15 \mathrm{~mm}$ & 99.75 & $90-100$ \\
$\quad<0.6 \mathrm{~mm}$ & 88.56 & $75-100$ \\
Hydrophilic coefficient & 0.71 & $<1$ \\
Plasticity index & 2.8 & $<4$ \\
\hline
\end{tabular}

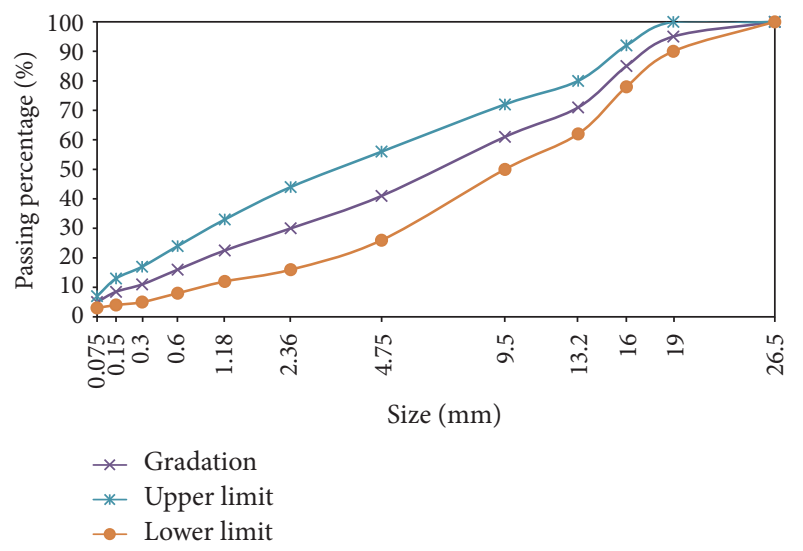

FIGURE 1: Gradation of aggregates in AC-20 asphalt mixture.

properties of the asphalt mixtures are shown in Table 7 after dynamic stability and tensile strength ratio tests.

The compaction parameters and volumetric properties of asphalt mixtures were displayed, and the dynamic stability and tensile strength ratio were tested. The dynamic stability and TSR of the modified asphalt mixtures increased compared to the base mixture, and the dynamic stability and TSR of DCLR-composite modified asphalt mixture were higher than those of other mixtures. This implies that the DCLR-composite modified asphalt mixture has better overall performance (high-temperature performance and moisture susceptibility) compared to other mixtures. It is possible that the rubber powder, SBS, and DCLR in the DCLRcomposite enhance the high-temperature performance and moisture resistance. The DCLR and SBS both can improve the resistance to rutting in asphalt mixtures, and it is deduced that the rubber powder could be effective to the enhancement of moisture resistance in asphalt mixtures.

\section{Results and Discussions}

4.1. Dynamic Modulus Test. The dynamic modulus of the asphalt mixture was tested by Universal Testing Machine (UTM-25). The test conditions of the dynamic modulus are that test temperatures are $5^{\circ} \mathrm{C}, 15^{\circ} \mathrm{C}, 35^{\circ} \mathrm{C}$, and $50^{\circ} \mathrm{C}$, and frequencies are $25 \mathrm{~Hz}, 10 \mathrm{~Hz}, 5 \mathrm{~Hz}, 1 \mathrm{~Hz}$, and $0.1 \mathrm{~Hz}$. The dynamic modulus and phase angle were collected during testing. The dynamic modulus is the ratio of stress to strain under different conditions, and the phase angle indicates the viscous part of asphalt mixtures. Dynamic modulus $\left(E^{*}\right)$ and phase angle $(\delta)$ of four asphalt mixtures are shown in Figures 2-5.

The dynamic moduli of DCLR and DCLR-composite modified asphalt mixtures were $17008 \mathrm{MPa}$ and $16723 \mathrm{MPa}$ at $15^{\circ} \mathrm{C}$ and $10 \mathrm{~Hz}$, respectively. Based on the definition of highmodulus asphalt mixture in France or China, the modulus of the mixture should be higher than $14000 \mathrm{MPa}$ at $15^{\circ} \mathrm{C}$ and $10 \mathrm{~Hz}$ [30-32]. DCLR and DCLR-composite modified asphalt mixtures met the technical standards of high-modulus asphalt mixtures. The dynamic moduli of the asphalt mixtures declined with the increase in temperature and increased with the increase in frequency. At the same temperature, the higher the frequency is, the higher the dynamic modulus of the asphalt mixture is. At a high temperature and low frequency, the dynamic modulus of asphalt mixture is minimum. Therefore, in the summer, it is potential that permanent deformations occur in the slow lanes and parking lots, such as rutting at high temperatures. Furthermore, the dynamic moduli of the asphalt mixtures increased rapidly in the range of $0.1 \mathrm{HZ}-5 \mathrm{~Hz}$ and increased slowly and approached stability when the frequency exceeded $5 \mathrm{~Hz}$.

The phase angle of asphalt mixtures is a key parameter to characterize the viscoelastic property. The smaller the phase 
TABLE 6: Volumetric indexes of the asphalt mixtures.

\begin{tabular}{|c|c|c|c|c|}
\hline Items & SK-90 asphalt mixture & $\begin{array}{l}\text { SBS modified asphalt } \\
\text { mixture }\end{array}$ & $\begin{array}{l}\text { DCLR modified } \\
\text { asphalt mixture }\end{array}$ & $\begin{array}{l}\text { DCLR-composite modified } \\
\text { asphalt mixture }\end{array}$ \\
\hline $\begin{array}{l}\text { Bulk relative specific } \\
\text { gravity } /\left(\mathrm{g} / \mathrm{cm}^{3}\right)\end{array}$ & 2.422 & 2.560 & 2.503 & 2.547 \\
\hline $\begin{array}{l}\text { Maximum theoretical } \\
\text { specific gravity } /\left(\mathrm{g} / \mathrm{cm}^{3}\right)\end{array}$ & 2.596 & 2.615 & 2.632 & 2.623 \\
\hline $\mathrm{VV} / \%$ & 4.4 & 4.5 & 4.3 & 4.6 \\
\hline VMA/\% & 13.3 & 13.3 & 13.2 & 13.3 \\
\hline VFA/\% & 68.1 & 65.2 & 67.4 & 66.5 \\
\hline $\mathrm{OAC} / \%$ & 4.2 & 4.2 & 4.2 & 4.3 \\
\hline
\end{tabular}

Note: VV: volume of air voids; VMA: volume of voids in mineral aggregate; VFA: volume of voids filled with asphalt; and OAC: optimum asphalt content.

TABLE 7: Performance of the asphalt mixtures.

\begin{tabular}{|c|c|c|c|c|}
\hline Types & Dynamic stability/(times/mm) & Failure strain $/ \mu \varepsilon$ & Residual stability/\% & TSR/\% \\
\hline SK-90 asphalt mixture & 943.88 & 2683 & 80.05 & 76.38 \\
\hline SBS modified asphalt mixture & 2452.38 & 2798 & 84.40 & 84.15 \\
\hline DCLR modified asphalt mixture & 2604.86 & 1552 & 83.64 & 83.78 \\
\hline DCLR-composite modified asphalt mixture & 9867.65 & 3070 & 100.05 & 86.61 \\
\hline
\end{tabular}

Note: DCLR: Direct Coal Liquefaction Residue; DCLR-composite: 2\% SBS, 15\% rubber powder and 10\% DCLR by mass of SK-90 asphalt binder; and TSR: tensile strength ratio.

angle is, the more elastic the asphalt mixture is. The larger the phase angle is, the more viscous the asphalt mixture is. When the temperature was lower than $35^{\circ} \mathrm{C}$, the phase angle of the asphalt mixtures decreased with the rise in frequency and declines at the range of $0.1 \mathrm{~Hz}-5 \mathrm{~Hz}$. When the temperature is higher than $35^{\circ} \mathrm{C}$, the phase angle of the asphalt mixtures increased with the increase of the frequency at the range of $0.1 \mathrm{~Hz}-1 \mathrm{~Hz}$ and stay stability after $1 \mathrm{~Hz}$. This indicates that the asphalt mixture is more elastic at a low temperature and high frequency; and asphalt mixture is more viscous at a high temperature and low frequency. Furthermore, it is found that the influence of the temperature on the viscoelasticity of asphalt mixtures is more than that of the frequency.

When the frequency was constant, the phase angle of asphalt mixture increased with the increase of temperature, and it indicates that asphalt mixture is more viscous at high temperatures. Asphalt mixtures demonstrated a more viscous state under high temperatures and low frequencies. The comparison of the dynamic modulus and phase angle of the asphalt mixtures at different temperatures under a loading frequency of $10 \mathrm{~Hz}$ is demonstrated in Figure 6, since this frequency is equivalent to a vehicle speed of $65-70 \mathrm{~km} / \mathrm{h}$ [33].

The dynamic moduli of DCLR and DCLR-composite modified asphalt mixtures were higher than those of SK-90 and SBS modified asphalt mixture at different temperatures at $10 \mathrm{~Hz}$. The dynamic moduli of the asphalt mixtures declined with the increase of temperature. The dynamic moduli of the asphalt mixtures declined slowly at $0^{\circ} \mathrm{C}-35^{\circ} \mathrm{C}$, while the dynamic moduli of the asphalt mixtures dropped fast and finally approached the same level at $35^{\circ} \mathrm{C}-50^{\circ} \mathrm{C}$. This indicates that the deformation resistance of asphalt mixture gradually declined with the increase of temperature. The DCLR and
DCLR-composite modified asphalt mixtures had a good resistance to deformation at high temperatures compared to SK-90 and SBS modified asphalt mixtures. The phase angles of DCLR and DCLR-composite modified asphalt mixture were lower than those of SK-90 and SBS modified asphalt mixture at different temperatures. The phase angle of the asphalt mixtures increased with the rise in temperature. The phase angle of the asphalt mixtures increased rapidly at $5^{\circ} \mathrm{C}-15^{\circ} \mathrm{C}$ and $35^{\circ} \mathrm{C}-50^{\circ} \mathrm{C}$, while at $15^{\circ} \mathrm{C}-35^{\circ} \mathrm{C}$, the phase angle of the asphalt mixtures increased slowly. This shows that the viscous part of the asphalt mixtures became strong with the rise in temperature. Compared to SK-90 and SBS modified asphalt mixtures, the DCLR and DCLR-composite modified asphalt mixture had a good elastic property. The phase angle of DCLR-composite modified asphalt mixture was smaller than that of DCLR modified asphalt mixture at a high temperature, which was due to the addition of SBS and rubber powders. It means that it is more elastic at high temperatures compared to the DCLR modified asphalt mixture.

4.2. Master Curve of the Dynamic Modulus. According to the time-temperature equivalent principle of viscoelastic materials, the dynamic modulus curve at different temperatures and frequencies can be composed into a smooth curve (master curve) at a reference temperature through a shift. The master curve can be used to predict the viscoelastic properties of asphalt mixtures at a low frequency or high frequency that is difficult to reach in the lab. The master curves of dynamic modulus of the asphalt mixtures were plotted in Figure 7 based on [34]

$$
\log \left(E^{*}\right)=\delta+\frac{\alpha}{1+e^{\beta+\lambda \lg \omega_{\text {red }}}},
$$



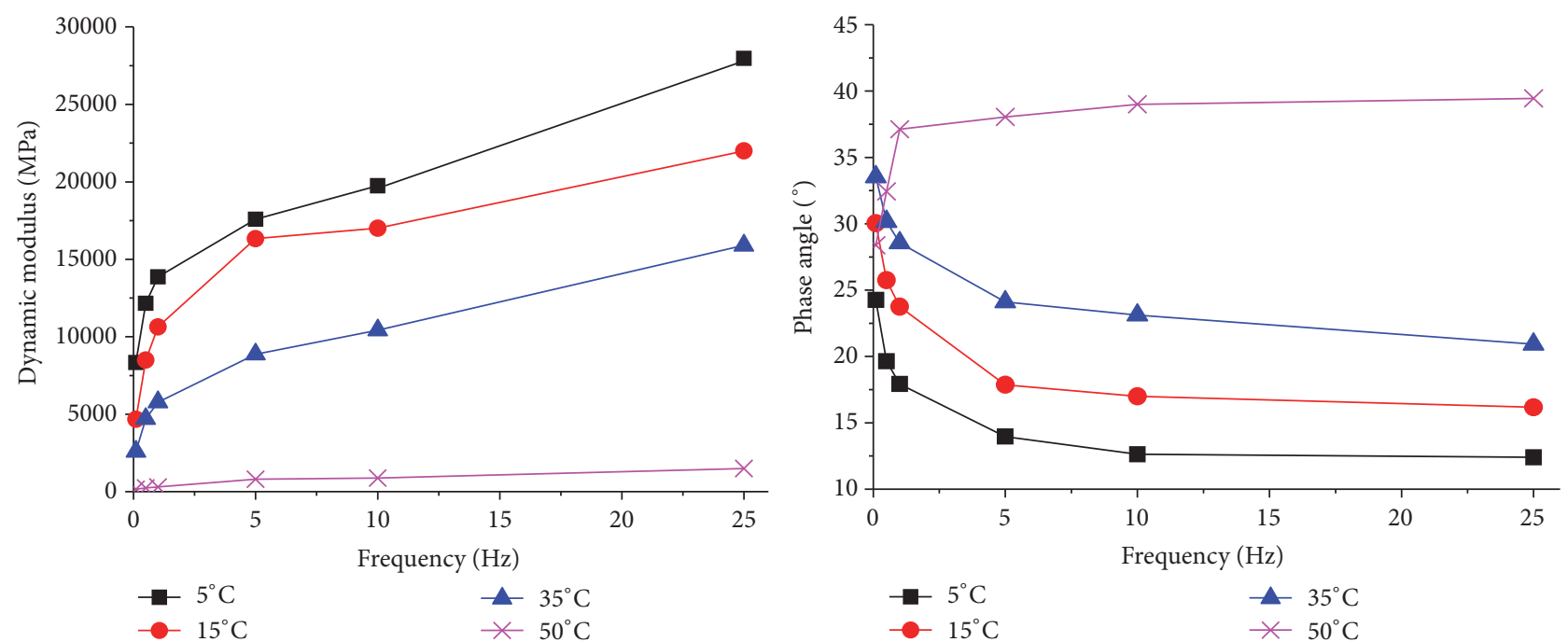

FIGURE 2: The dynamic modulus and phase angle of DCLR modified asphalt mixture.
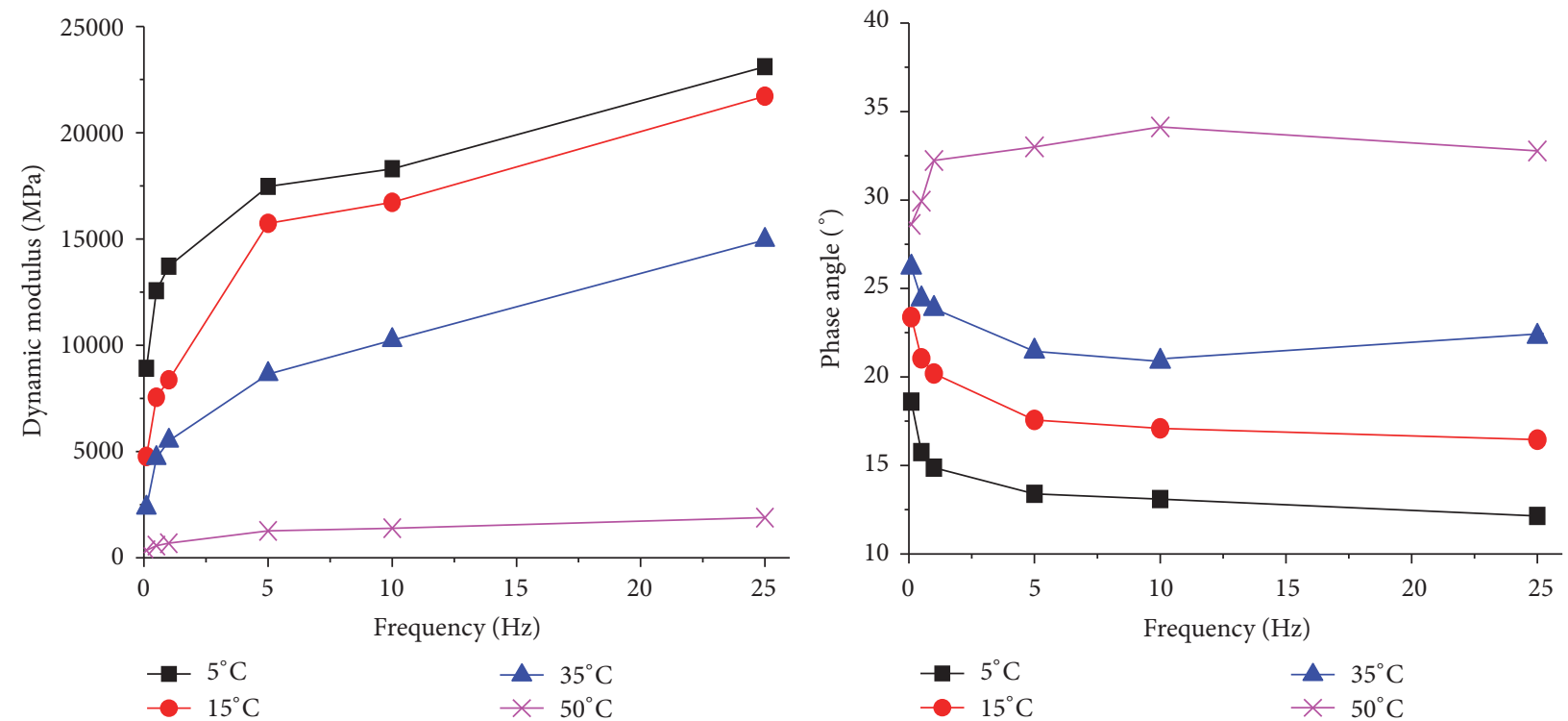

FIGURE 3: The dynamic modulus and phase angle of DCLR-composite modified asphalt mixture.

where $E^{*}$ is the dynamic modulus of asphalt mixtures; $\omega_{\text {red }}$ is the reduced frequency under the reference temperature; $\lambda$, $\alpha, \beta$, and $\omega$ are the regression coefficients.

It can be seen from Figure 7 that the master curve tended to change slowly and approach an asymptote. The DCLRcomposite modified asphalt mixture had the highest dynamic modulus value. The order is followed by the DCLR, SBS, and SK-90 asphalt mixtures. The dynamic moduli of DCLR and DCLR-composite modified asphalt mixtures were closer and higher than those of the SK-90 and SBS modified asphalt mixtures when the loading frequency was higher than $0.1 \mathrm{~Hz}$. The dynamic modulus of the asphalt mixtures increased after the addition of DCLR and DCLR-composite, and this indicates that this addition improves the resistance to permanent deformation in the asphalt mixtures at high temperatures. It is likely that the DCLR and DCLR-composite modified asphalt mixtures could be used for the parking lots or slow lanes due to the effective prevention of permanent deformations.

4.3. Christensen-Anderson-Marasteanu (CAM) Model. On the basis of the Christensen-Anderson (CA) model, the Christensen-Anderson-Marasteanu (CAM) model was further developed. The CAM model has a clearly physical meaning [35] compared to the CA model. This paper used the CAM model to study the viscoelastic behaviors of DCLR and DCLR-composite modified asphalt mixtures. The CAM model mainly consists of four equations: the complex modulus master curve, the storage modulus master curve, the phase angle, and the temperature-displacement factor. 

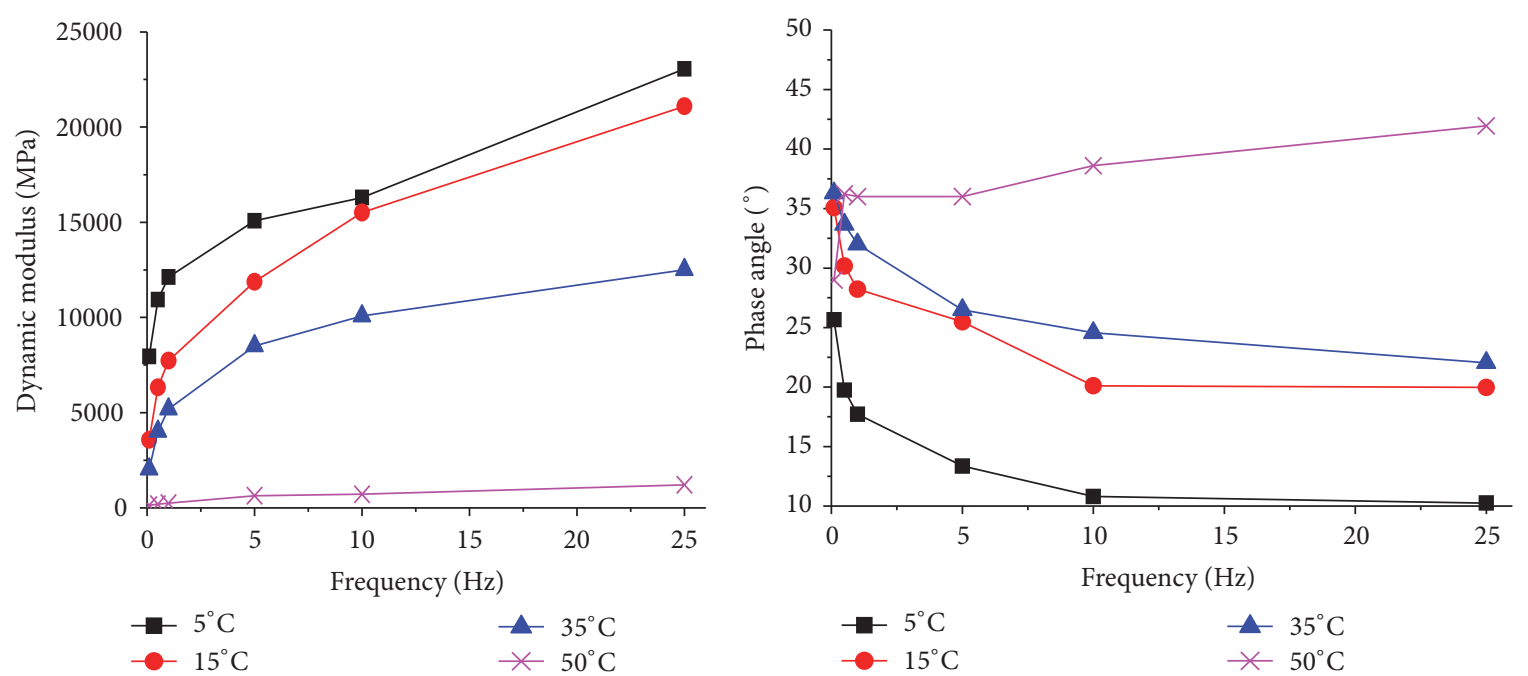

FIgUre 4: The dynamic modulus and phase angle of SBS modified asphalt.
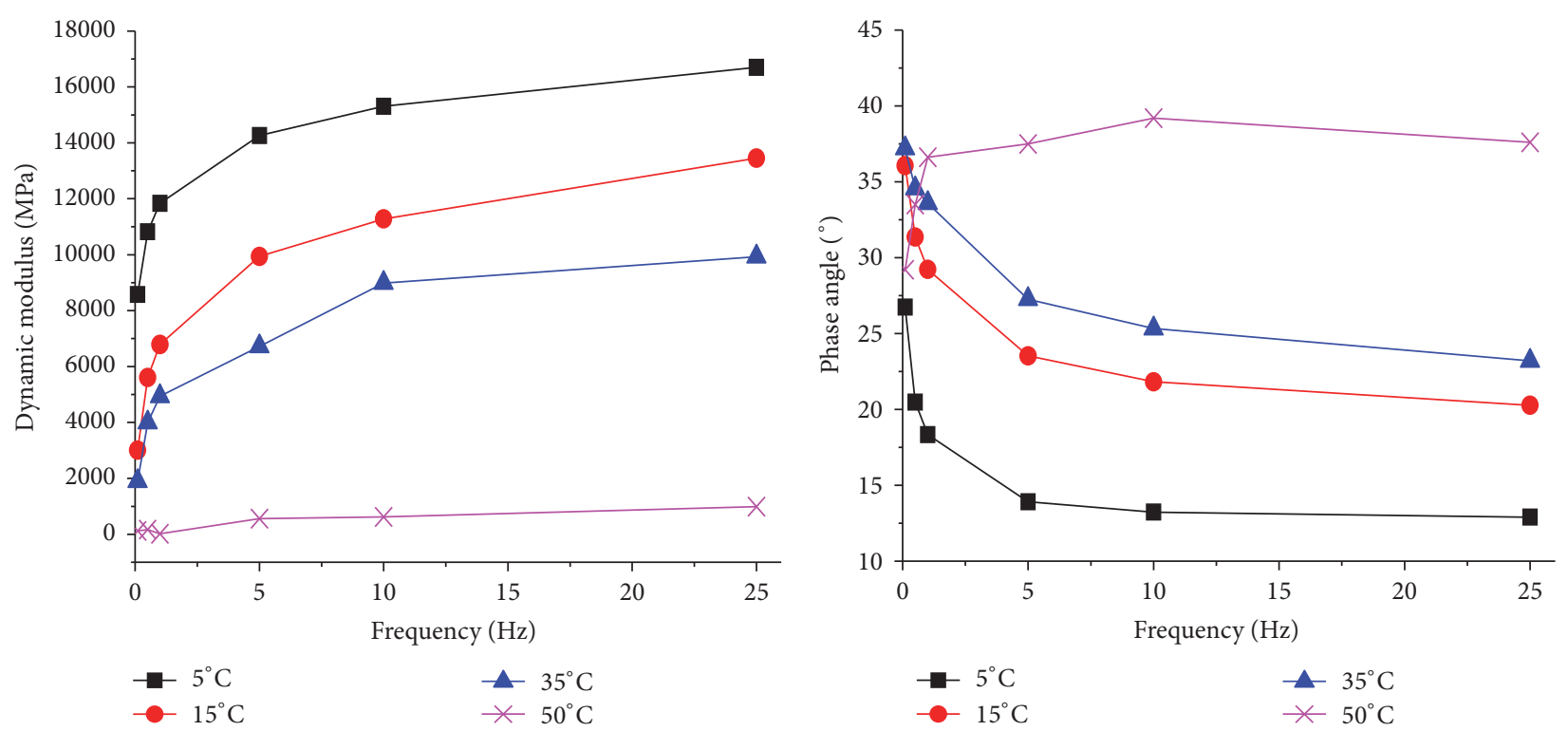

FIGURE 5: The dynamic modulus and phase angle of SK-90 asphalt mixture.

4.3.1. Master Curve for the Complex Modulus. The equation for describing the complex modulus master curve of asphalt mixtures in the CAM model is shown in formula (2). The starting frequency when the master curve enters into the high temperature or low frequency limit state is defined as the second limit frequency. The range between the two limit frequencies is called the rheological region. In this range, the rheological properties of asphalt mixture were affected by frequency and temperature, and the phase change of asphalt mixture mainly occurred in this region. The regions outside the two limit frequencies are called the low frequency steady state zone and the high frequency steady state zone. In these zones, the rheological properties of asphalt mixture were not affected by the frequency or temperature. The modulus corresponding to the limit frequency of low frequency steady state is called the complex modulus in equilibrium state $G_{e}^{*}$, and the modulus corresponding to the limit frequency of high frequency steady state is called the complex modulus in the glass state $G_{g}^{*}$. In addition, the turning point, of which asphalt mixtures transition from a low frequency steady state to a rheological region, it is called the low frequency turning point $f_{c}$. The changing point, of which asphalt mixtures transition from rheological to a high frequency steady state, is defined as the high frequency turning point $f_{c}^{\prime}$. The intercept of $G_{e}^{*}$ and $G_{g}^{*}$ in logarithmic coordinates is denoted $R$ (see (3)), which relates to morphological parameters $m$ and $k$. A high $R$ value indicates that the change from the elastic behavior to the viscous behavior is easier.

$$
G^{*}=G_{e}^{*}+\frac{G_{g}^{*}-G_{e}^{*}}{\left[1+\left(f_{c} / f^{\prime}\right)^{k}\right]^{m_{e} / k}},
$$



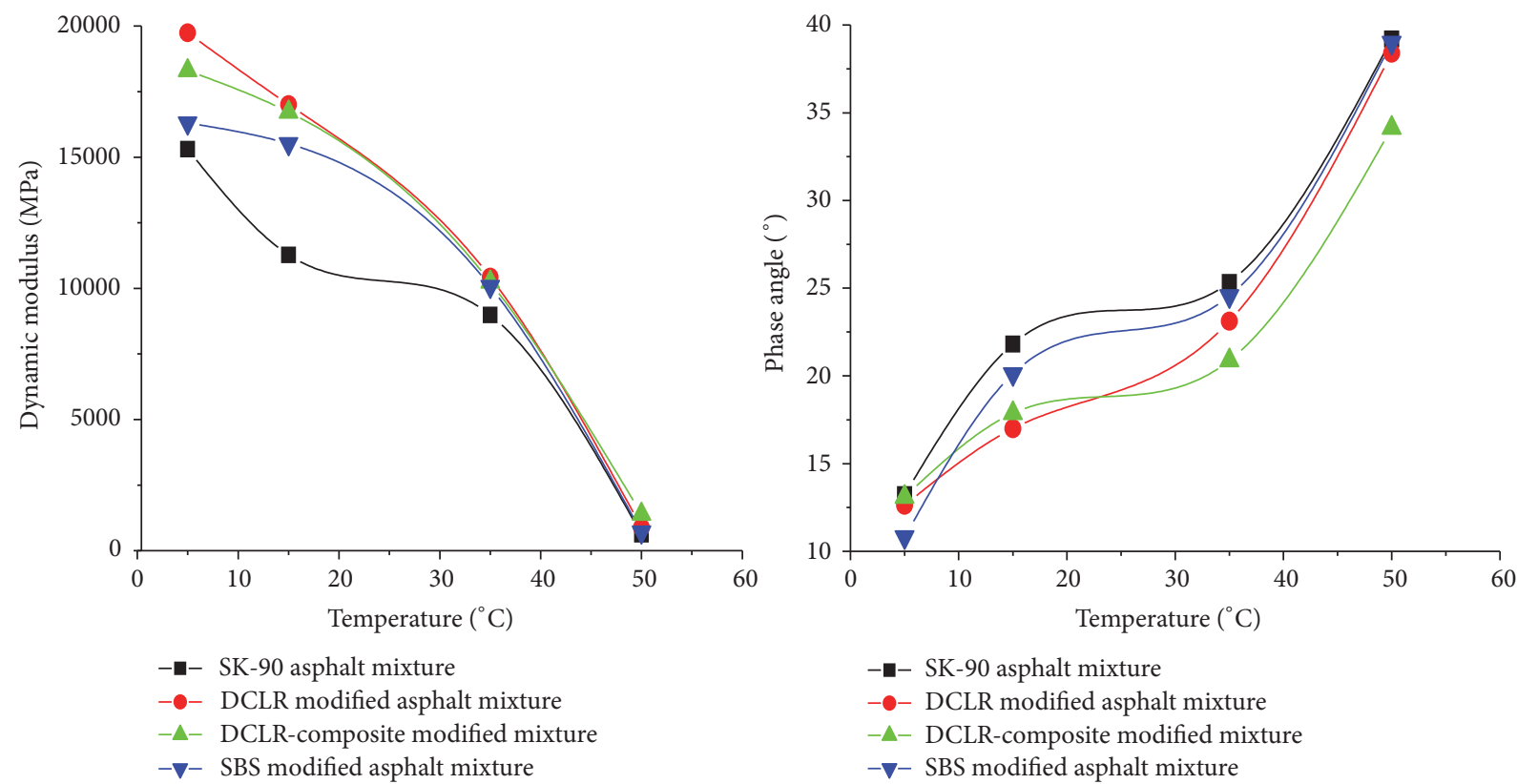

FIgURE 6: Comparison of dynamic modulus and phase angle between the asphalt mixtures at $10 \mathrm{~Hz}$.

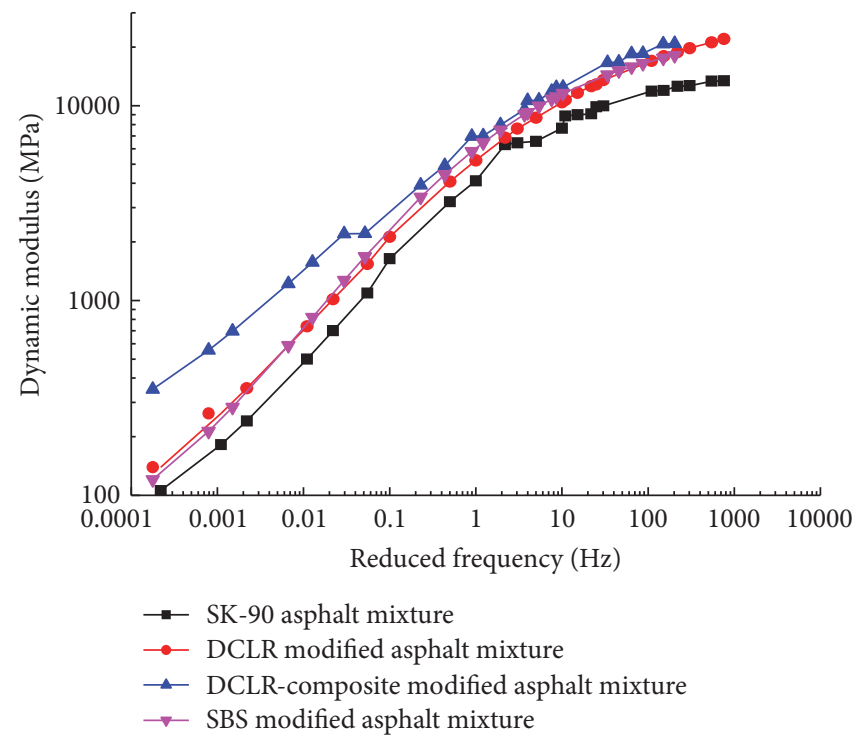

FIgURE 7: The dynamic modulus master curves of the four asphalt mixtures.

$$
R=\log \frac{2^{m_{c} / k}}{1+\left(2^{m_{c} / k}-1\right)\left(G_{e}^{*} / G_{g}^{*}\right)},
$$

where $G^{*}$ is the dynamic modulus; $G_{e}^{*}$ is the complex modulus of the equilibrium state; $G_{g}^{*}$ is the complex modulus of the glass state; $f_{c}$ is the elastic limit threshold, which is the critical frequency for asphalt mixture transitioning from the viscous flow zone into the rheological zone; $m_{e}$ and $k$ are the dimensionless morphological parameters.

4.3.2. Dynamic and Viscoelastic Properties of Asphalt Mixtures. Based on the curve fitting by the CAM model, the viscoelastic parameters of the CAM model are shown in Figure 8. Different parameters relate to different properties in asphalt mixtures, and the results and discussions are shown as follows.

The parameter $G_{e}^{*}$ describes the resistance to rutting in asphalt mixtures at high temperatures. The parameter $G_{e}^{*}$ results of DCLR and DCLR-composite modified asphalt mixtures were much larger than those of SK-90 and SBS modified asphalt mixture. This shows that the addition of DCLR and DCLR-composite can significantly improve the rutting resistance of asphalt mixtures at high temperatures. The parameters $G_{g}^{*}$ and $f_{c}$ depict the resistance to permanent deformation in asphalt mixtures at low temperatures. The coefficients 


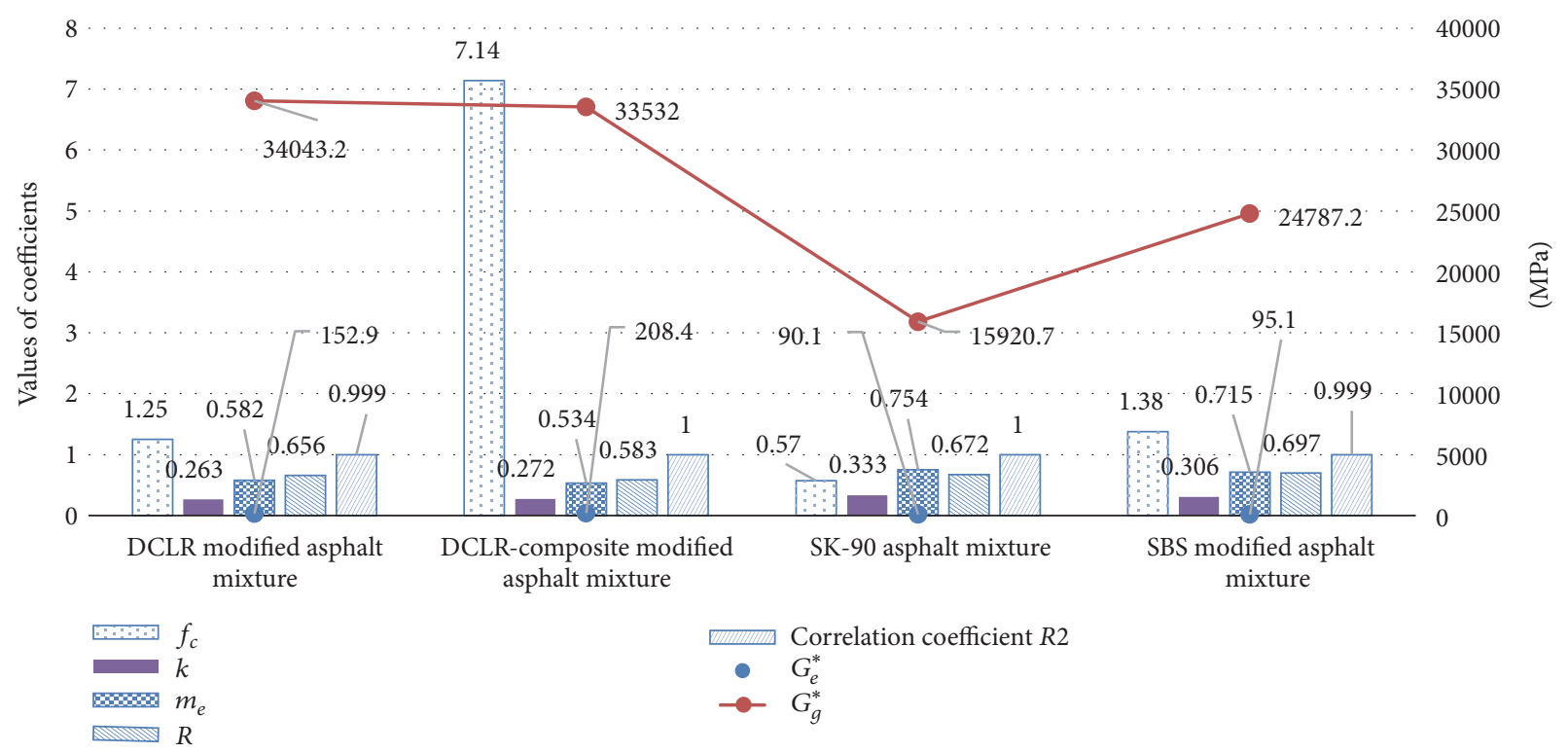

FIGURE 8: Viscoelastic parameters of the CAM model.

$G_{g}^{*}$ and $f_{c}$ of DCLR and composite DCLR modified asphalt mixtures were higher than those of SK-90 and SBS modified asphalt mixture. It indicates that the DCLR and DCLRcomposite modified asphalt mixtures have a better resistance to deformation at low temperatures or high frequencies. Small $m_{e}$ and $R$ represent a less sensitivity to the frequency since $m_{e}$ and $R$ denote the sensitivity of asphalt mixtures to the frequency. The SBS modified asphalt mixture has an easy transition from the elastic part to the viscous part compared to other mixtures. Based on the results of the curve fitting, the DCLR and DCLR-composite modified asphalt mixtures had a lower sensitivity to the frequency. The correlation degrees of CAM model fitting of the asphalt mixtures were all above 0.999 , which proves that the CAM model can characterize the viscoelastic behavior of the asphalt mixtures.

\section{Conclusions}

The DCLR and DCLR-composite were used to modify the base asphalt binder, and the properties of modified asphalt mixtures were analyzed compared to SK-90 and SBS modified asphalt mixtures. The viscoelastic properties of asphalt mixtures were studied using the CAM model, and the following conclusions can be drawn.

(1) The DCLR and DCLR-composite modified asphalt mixtures had higher dynamic moduli and smaller phase angles than those of the SK-90 and SBS modified asphalt mixtures. This indicates that the DCLR and DCLR-composite modified asphalt mixtures are more elastic compared to the SK-90 and SBS mixtures.

(2) The dynamic modulus of the DCLR-composite modified asphalt mixture was higher than those of other mixtures when the frequency was smaller than $0.1 \mathrm{~Hz}$. Otherwise, the dynamic moduli of the DCLR and DCLR-composite modified asphalt mixtures were close to each other and higher than those of SK-90 and SBS modified asphalt mixtures. The high- and low-temperature performance of the DCLR-composite modified asphalt mixture were better than the other mixtures, as well as the DCLR modified asphalt mixtures.

(3) The utilization of the CAM model helps analyze the viscoelastic properties of asphalt mixtures, and a good fit and correlation are observed. The resistance to permanent deformation in asphalt mixtures was enhanced by the addition of the DCLR and DCLRcomposite in the base asphalt mixture. The DCLR and DCLR-composite modified asphalt mixtures exhibited a less sensitivity to the frequency based on the parameter results of the CAM model, such as coefficients $m_{e}$ and $R$.

\section{Competing Interests}

The authors declare that they have no competing interests.

\section{Acknowledgments}

This project is supported by the Importation and Development of High-Caliber Talents Project of Beijing Municipal Institutions (Grant no. PXM2013-014210-000165) and the National Natural Science Foundation of China (51478028). The authors wish to express their gratitude to Mr. Jinqi Gao for his assistance in the laboratory work. 


\section{References}

[1] H. S. R. I. o. M. o. Communications, Standard Test Methods for Asphalt and Asphalt Mixtures for Highway Engineering (JTG E20-2011), People’s Communication Press, Beijing, China, 2011.

[2] M. W. Witzcak, Simple Performance Test for Superpave Mix Design, vol. 465, Transportation Research Board, 2002.

[3] A. Loizos, G. Boukovalas, and A. Karlaftis, "Dynamic stiffness modulus for pavement subgrade evaluation," Journal of Transportation Engineering, vol. 129, no. 4, pp. 434-443, 2003.

[4] R. F. Bonaquist, Precision of the Dynamic Modulus and Flow Number Tests Conducted with the Asphalt Mixture Performance Tester, vol. 702, Transportation Research Board, 2011.

[5] M. W. Witczak, Specification Criteria for Simple Performance Tests for Rutting, vol. 1, Transportation Research Board, 2007.

[6] R. F. Bonaquist, Ruggedness Testing of the Dynamic Modulus and Flow Number Tests with the Simple Performance Tester, 2008.

[7] Y. Zhang, R. Luo, and R. L. Lytton, "Characterizing permanent deformation and fracture of asphalt mixtures by using compressive dynamic modulus tests," Journal of Materials in Civil Engineering, vol. 24, no. 7, pp. 898-906, 2012.

[8] A. K. Apeagyei, "Rutting as a function of dynamic modulus and gradation," Journal of Materials in Civil Engineering, vol. 23, no. 9, pp. 1302-1310, 2011.

[9] H. Zhu, L. Sun, J. Yang, Z. Chen, and W. Gu, "Developing master curves and predicting dynamic modulus of polymer-modified asphalt mixtures," Journal of Materials in Civil Engineering, vol. 23, no. 2, pp. 131-137, 2011.

[10] J.-C. Wei, S.-P. Cui, and J.-B. Hu, "Research on dynamic modulus of asphalt mixtures," Journal of Building Materials, vol. 11, no. 6, pp. 657-661, 2008.

[11] T. R. Clyne, M. O. Marasteanu, X. Li et al., Dynamic and Resilient Modulus of Mn/DOT Asphalt Mixtures, Minnesota Department of Transportation: Department of Civil Engineering, University of Minnesota, 2003.

[12] T. Pellinen and M. Witczak, "Stress dependent master curve construction for dynamic (complex) modulus (with discussion)," Journal of the Association of Asphalt Paving Technologists, vol. 71, pp. 281-309, 2002.

[13] M. Witczak, D. Andrei, and W. Houston, "Development of the 2002 guide for the design of new and rehabilitated pavement structures," Inter Team Technical Report (Seasonal 1), Resilient Modulus as Function of Soil Moisture-Summary of Predictive Models, College of Engineering and Applied Sciences, Department of Civil and Environmental Engineering, Arizona State University, 2000.

[14] J. P. Hallin, "Development of the 2002 guide for the design of new and rehabilitated pavement structures: phase II," Report for National Cooperative Highway Research Program, Transportation Research Board, National Research Council, 2004.

[15] E. Chailleux, G. Ramond, C. Such, and C. De La Roche, "A mathematical-based master-curve construction method applied to complex modulus of bituminous materials," Road Materials and Pavement Design, vol. 7, no. s1, pp. 75-92, 2006.

[16] X. Zhang, F. Chi, L. Wang, and J. Shi, "Study on viscoelastic performance of asphalt mixture based on CAM model," Journal of Southeast University, vol. 24, no. 4, pp. 498-502, 2008.

[17] Y. Yin, Research on Dynamic Viscoelastic Characteristics and Shear Modulus Predicting Methods for Aspgalt Mixtures Based on Dynamic Mechanical Analysis (DMA) Means, South China University of Technology, Guangzhou, China, 2010.
[18] C. Wu and K. Xie, Direct Coal Liquefaction, Chemical Industry Press, Beijing, China, 2010.

[19] W. Zhang, J. Jin, H. Yu, and L. Tian, "Coal direct hydrogenation liquefaction process," Clean Coal Technology, vol. 7, no. 3, pp. 31-33, 2001.

[20] X. Gu, "Properties and utilization of coal direct liquefaction residue," Clean Coal Technology, vol. 18, no. 3, pp. 24-31, 2012.

[21] S. Khare and M. Dell'Amico, "An overview of conversion of residues from coal liquefaction processes," The Canadian Journal of Chemical Engineering, vol. 91, no. 10, pp. 1660-1670, 2013.

[22] L. He, Study on the preparation and performance of asphalt modified by coal liquefaction residue [M.S. thesis], Highway School, Chang'an University, Xian, China, 2013.

[23] Y. Zhang, Exploratory Study on Direct Coal Liquefaction Residue Modified Asphalt, Engineering, Northwest University, Xian, China, 2012.

[24] Y.-S. Zhao and J. Ji, "Study on the performance of direct coal liquefaction residue modified mixture asphalt," in Challenges and Advances in Sustainable Transportation Systems: Plan, Design, Build, Manage, and Maintain, p. 319, ASCE, 2014.

[25] J. Ji, Y.-S. Zhao, and S. F. Xu, "Study on properties of the blends with direct coal liquefaction residue and asphalt," Applied Mechanics and Materials, vol. 488-489, pp. 316-321, 2014.

[26] D.-R. Zhang, R. Luo, Y. Chen, S.-Z. Zhang, and Y. Sheng, "Performance analysis of DCLR-modified asphalt based on surface free energy," China Journal of Highway and Transport, vol. 29, no. 1, pp. 22-28, 2016.

[27] Q. Zhang, H. Pei-wen, and B. Zheng-yu, "Research on preparation and adhesion of emulsified asphalt modified with waterborne epoxy resin," Journal of Highway and Transportation Research and Development, no. 9, pp. 9-14, 2015.

[28] J. Chen, M. Sun, X.-M. Dai et al., "Asphalt modification with direct coal liquefaction residue based on benzaldehyde crosslinking agent," Journal of Fuel Chemistry and Technology, no. 9, pp. 1052-1060, 2015.

[29] Z. Liu, H. Song, Z. Ma et al., "Preparation of mesophase pitch from the residue of coal liquefaction by solvent hydrogenation," Carbon Techniques, no. 2, pp. 18-22, 2016.

[30] J.-F. Corte, "Development and uses of hard-grade asphalt and of high-modulus asphalt mixes in France," Transportation Research Circular, vol. 503, pp. 12-31, 2001.

[31] T. C. R. I. o. L. Province, Technical Specification Construction of High Modulus Asphalt Mixture (DB21/T 1754-2009), People's Communication Press, Beijing, China, 2009.

[32] X. Li, Mechanical Engineering and Control Systems: Proceedings of the 2015 International Conference on Mechanical Engineering and Control Systems (MECS2015), World Scientific Publishing, 2016.

[33] G. A. Tannoury and R. C. E. University of Nevada, Laboratory Evaluation of Hot Mix Asphalt Mixtures for Nevada's Intersections_Phase II, University of Nevada, Reno, Nev, USA, 2007.

[34] H. Yao, Z. You, L. Li, S. W. Goh, and C. Dedene, "Evaluation of the master curves for complex shear modulus for nano-modified asphalt binders," in Proceedings of the 12th COTA International Conference of Transportation Professionals (CICTP '12), pp. 3399-3414, August 2012.

[35] M. Zeng, H. U. Bahia, H. Zhai, M. R. Anderson, and P. Turner, "Rheological modeling of modified asphalt binders and mixtures (with discussion)," Journal of the Association of Asphalt Paving Technologists, vol. 70, pp. 403-441, 2001. 

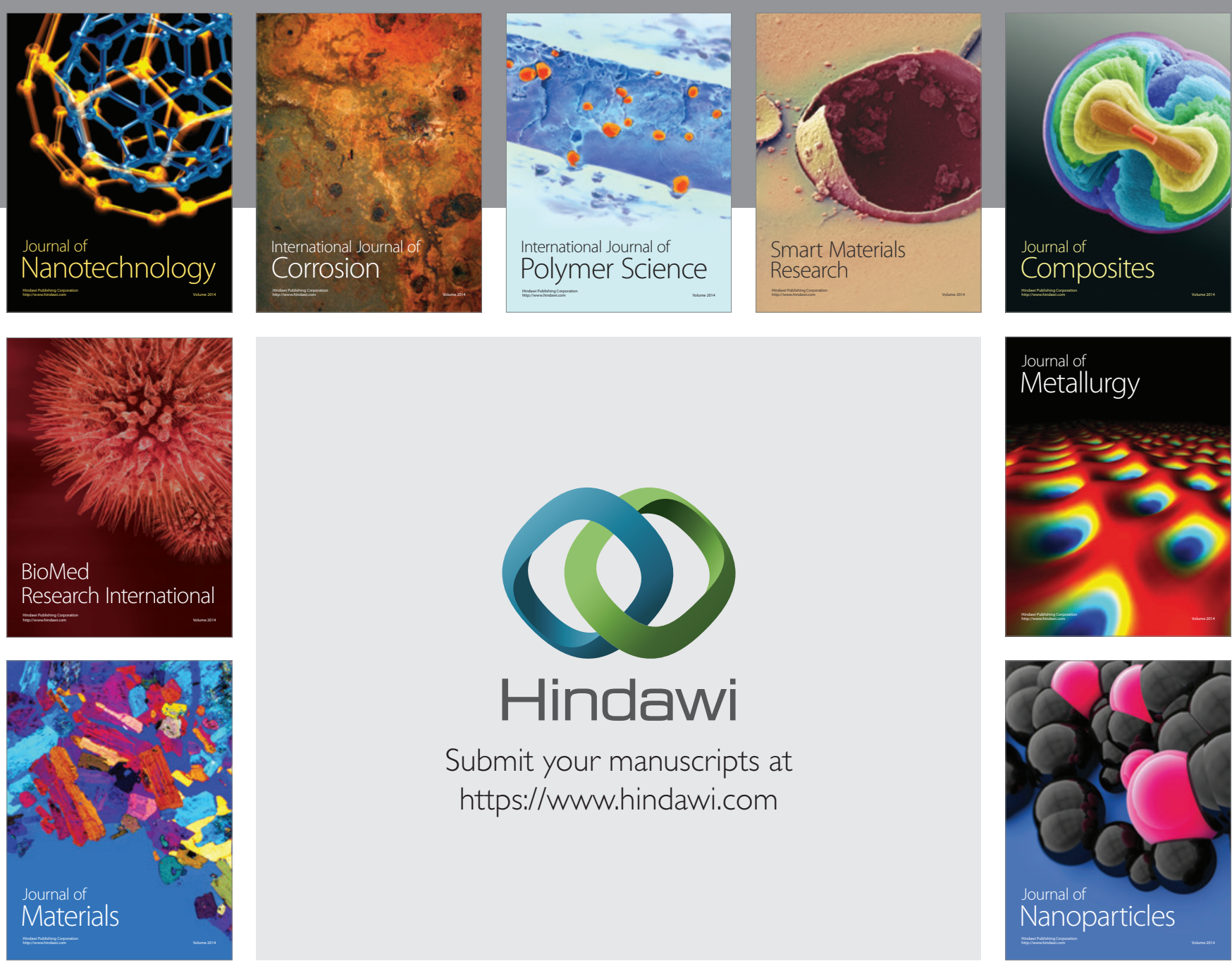

\section{Hindawi}

Submit your manuscripts at

https://www.hindawi.com

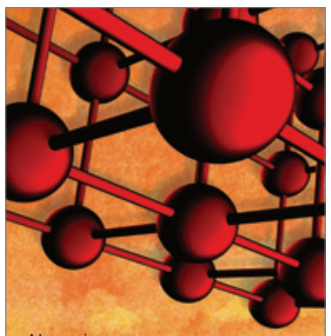

Materials Science and Engineering
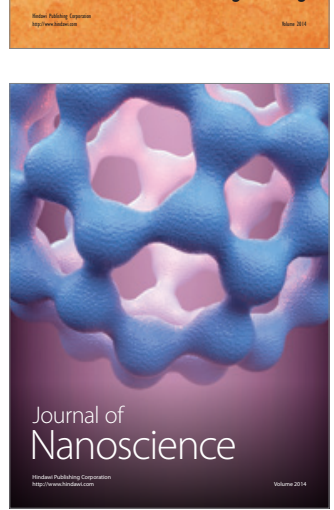
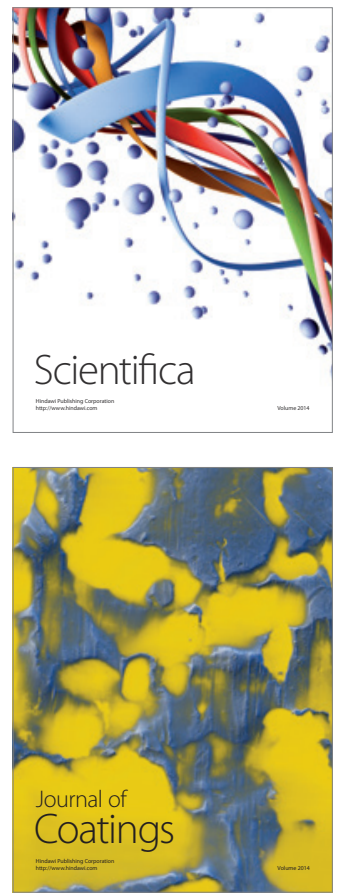
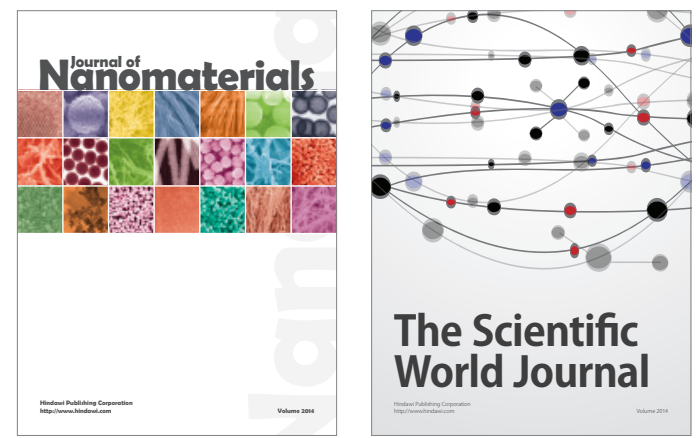

The Scientific World Journal
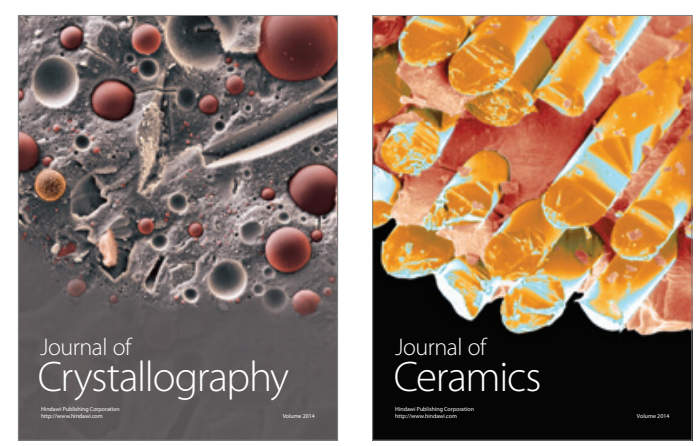
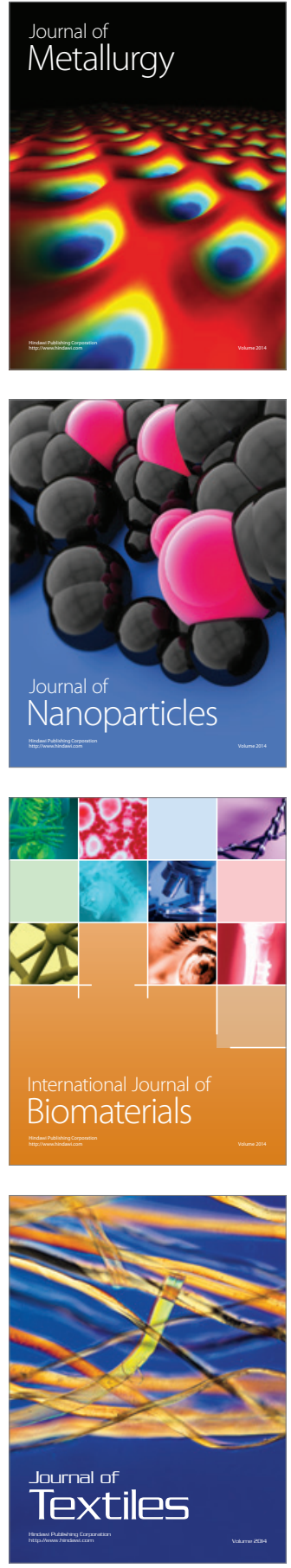